Nathaniel W. Yang, MD

Department of Otorhinolaryngology College of Medicine - Philippine General Hospital University of the Philippines Manila

Philippine National Ear Institute National Institutes of Health University of the Philippines Manila
Correspondence: Nathaniel W. Yang, MD Department of Otorhinolaryngology Ward 10, Philippine General Hospital Taft Ave., Ermita, Manila 1000 Phone: (632) 5264360 Fax: (632) 5255444

Emai: nwyang@gmx.net Reprints will not be available from the author.

\section{Pneumolabyrinth: Radiologic Evidence of Labyrinthine Injury}

A U.S. serviceman presented with a three-month history of unsteadiness on ambulation and increasing episodes of vertigo whenever he turned his head rapidly to the right. He had previously been injured in a bomb blast while stationed in Iraq four months prior to consultation. Aside from multiple soft tissue and bone trauma, he had also experienced vertigo and nearly complete deafness in the right ear immediately after the blast. Medical records indicated the presence of a traumatic perforation of the right tympanic membrane and spontaneous nystagmus on initial emergency medical assessment after the incident. Physical examination on consultation revealed bilaterally intact eardrums, a positive right head impulse test and a normal Romberg test. Audiometry showed a severe right SNHL. A presumptive diagnosis of a persistent perilymph fistula secondary to inner ear barotrauma was entertained, and supported by findings on temporal bone CT imaging.

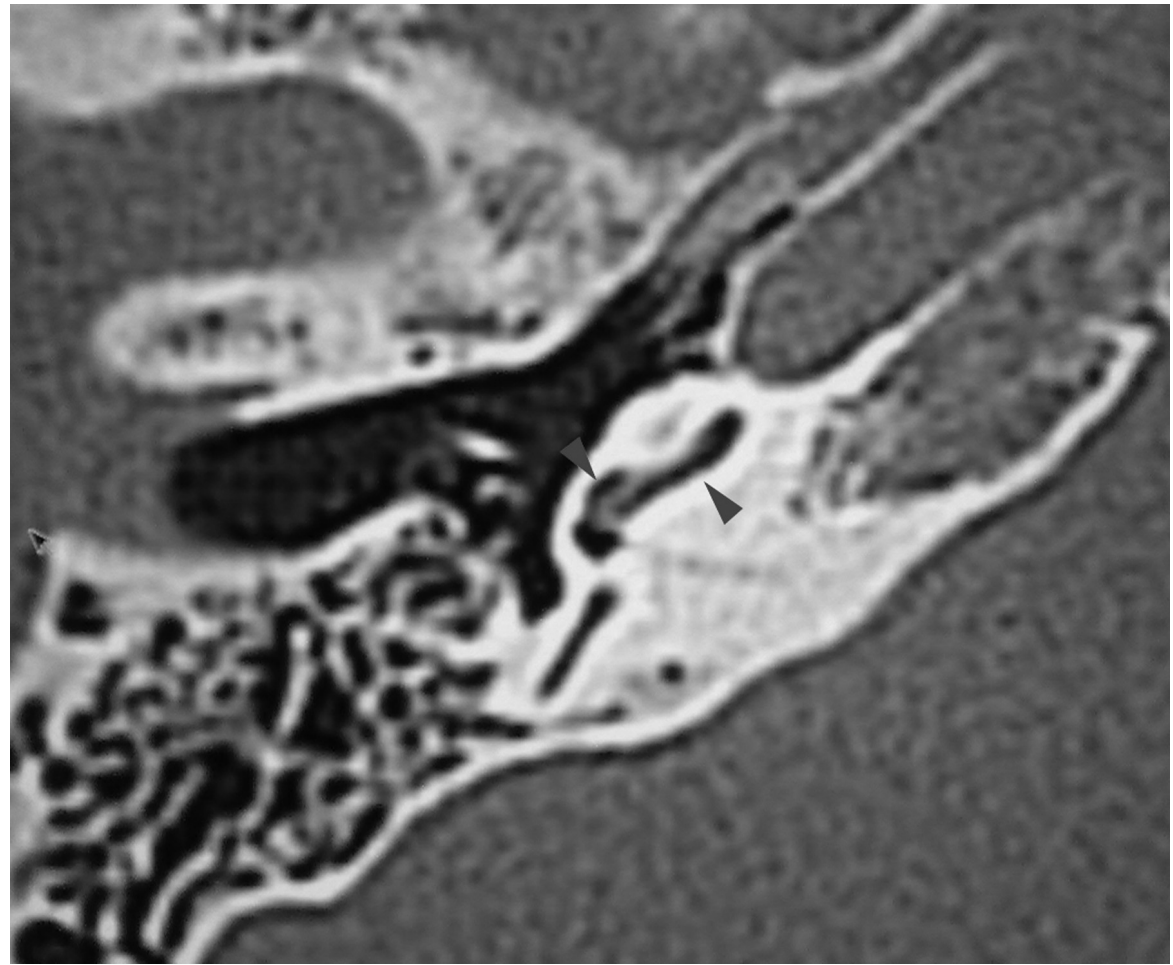

Figure 1 is the axial CT image of the patient's inner ear at the level of the basal turn of the cochlea. Two linear lucencies are visible within the cochlea (arrowheads). These have the same signal characteristics as the normal external auditory canal and middle ear space. As such, they indicate the presence of air within the cochlea - a condition termed pneumolabyrinth. 


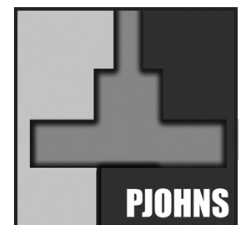

FROM THE VIEWBOX

Philippine Journal Of Otolaryngology-Head And Neck Surgery

Vol. 23 No. 2 July - DeCEMBER 2008

PJOHLS

Barotrauma from blast injuries and traumatic tympanic membrane perforations may cause perilymph fistulas. This is probably due to a sudden pressure wave transmitted through the tympanic membrane that results in an inward rupture of the round window membrane or an inward displacement of the stapedial footplate.' Pneumolabyrinth has been identified in patients suffering from perilymph fistulas due to barotrauma, ${ }^{2}$ and therefore can bolster the diagnosis when identified in the appropriate clinical setting. It has also been identified in patients with perilymph fistulas from other causes, including iatrogenic stapes fractures during mastoid surgery, temporal bone fractures, cholesteatoma, neoplasms of the temporal bone, stapedectomy and after cochlear implantation. ${ }^{3}$

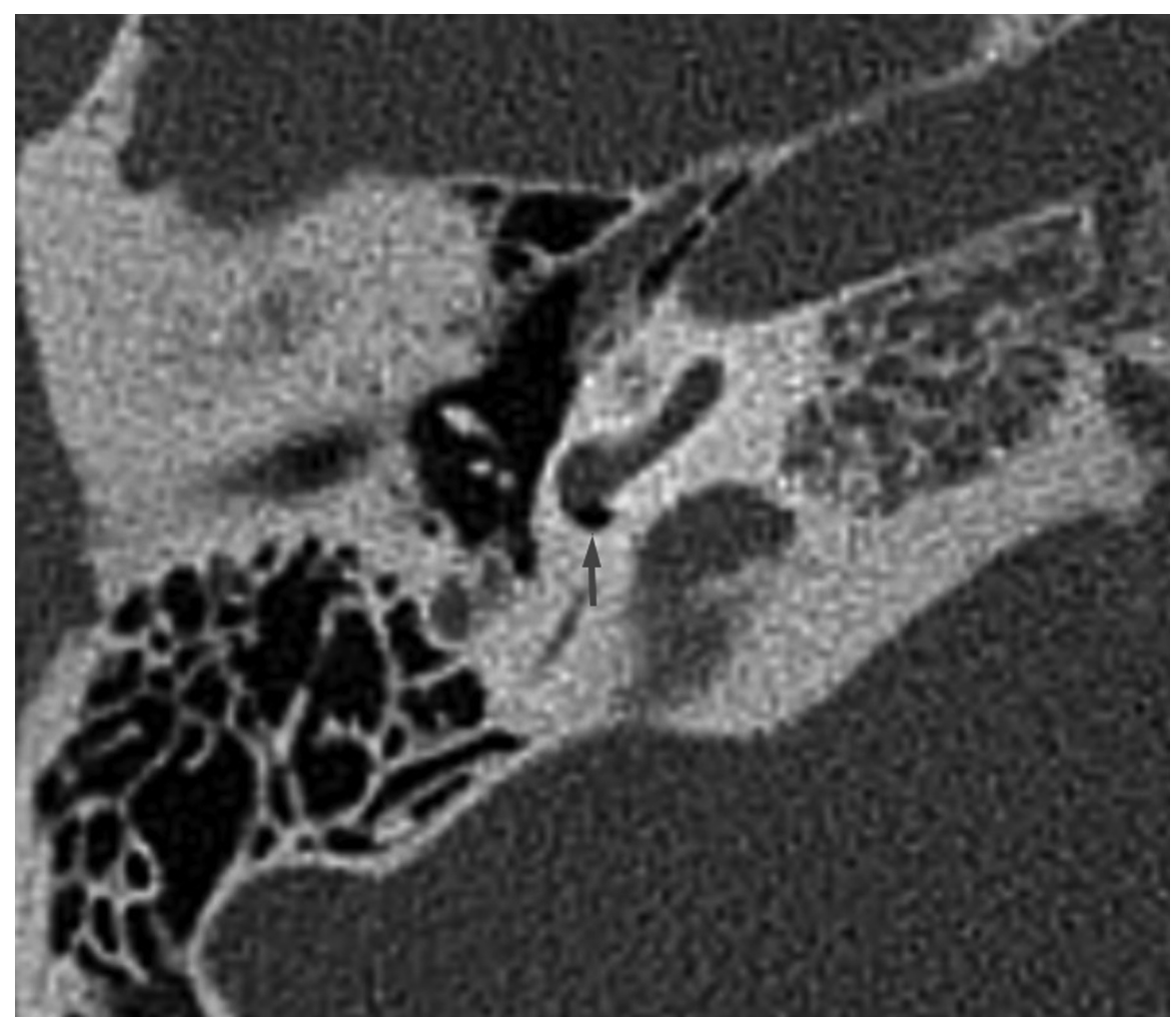

Figure 2 shows a normal cochlea at the same level for comparison. Note the uniform soft tissue density within the cochlear lumen, representing the endocochlear fluids. The lucency in the round window niche (thin arrow) also represents air but this is a normal finding.

REFERENCES:

1. Emmett JR, Shea JJ. Traumatic perilymph fistula. Laryngoscope 1980; 90: 1513-1519.

2. McGhee MA, Dornhoffer JL. A case of barotrauma-induced pneumolabyrinth secondary to perilymphatic fistula. Ear Nose Throat J 2000; 79: 456-459.

3. Lao WW, Niparko JK. Assessment of changes in cochlear function with pneumolabyrinth after middle ear trauma. Otology \& Neurotology 2007; 28: 1013-1017. 